Rev. Roum. Chim.,
ACADEMIA ROMÂNĂ
Revue Roumaine de Chimie
http://web.icf.ro/rrch/

\title{
EXTRACTION OF CERIUM(III) FROM AQUEOUS SOLUTION USING EMULSION LIQUID MEMBRANE-DESIGN OF EXPERIMENTS METHODOLOGY
}

\author{
Aziza HACHEMAOUI \\ Laboratory of Organic Materials, Process Engineering Department, Faculty of Technology, \\ University of Bejaia, DZ-06000, Algeria
}

Received October 30, 2019

An experimental study on extraction of cerium (Ce) from aqueous solutions using emulsion liquid membrane containing bis-(2-ethylhexyl) phosphoric acid (D2EHPA) as extractant was carried out. The effects of various operating parameters such as extractant and surfactant concentrations, mixing speed, $\mathrm{pH}$ of feed phase solution, concentration of stripping solution, phase ratio and treatment ratio on extraction of cerium has been experimentally investigated. The parameters mentioned were investigated and optimum conditions were determined. In this paper the full factorial design of experiments was used to model the extraction of $\mathrm{Ce}$ (III) from aqueous solution by emulsion liquid membrane. The results showed that the experimental and predicted values were in good agreement.

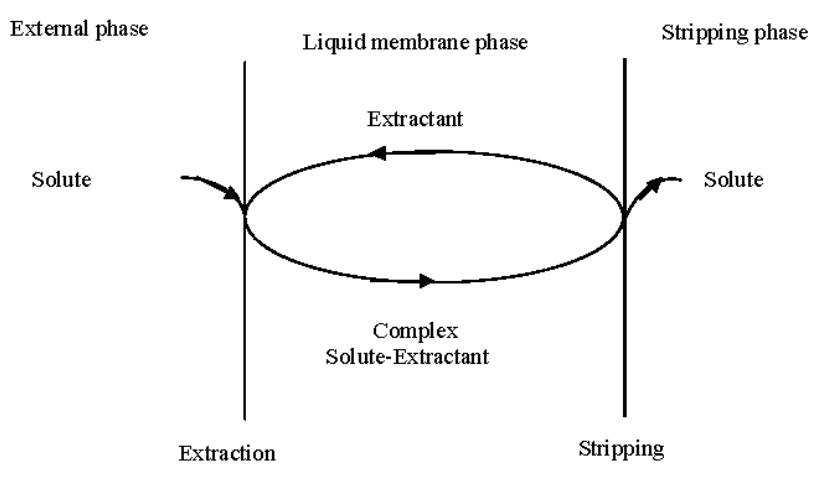

\section{INTRODUCTION}

Rare-earth elements have been used in various fields, such as electronics, magnetism, phosphors, metallurgy, catalysts, laser and ceramic technology. ${ }^{1-4}$ Cerium is one of the most abundant lanthanides rare earth metals; it is extracted from Monazite, allanite and bastnasite minerals. ${ }^{5}$

Solvent extraction is one of the first techniques used for the separation and recovery of rare-earth metals. $^{6-12}$ However, this traditional technique required a large quantity of solvent and high capital cost. Recently, emulsion liquid membrane (ELM) has been used as an alternative technique for separation and concentration of different solutes from dilute aqueous solutions. ${ }^{13}$ Compared to solvent extraction process, separation and concentration can be achieved in only one step, with very high mass transfer rate due to its large surface area within the emulsion globules. ${ }^{14-16}$

Emulsion liquid membrane is a double emulsion of type water-in-oil-in water $(\mathrm{W} / 0 / \mathrm{W})$, it formulated by dispersion of emulsion water-in-oil (w/o) containing of organic and aqueous stripping phase into the external phase containing solutes to be extracted. The organic phase consists of extractant, surfactant and diluent. A complex solute-extractant, formed at the interface of the emulsion globule and the external phase, diffuse through the organic phase, and then stripped into the stripping phase. ${ }^{17}$

As emulsion liquid membrane depends on several variables such as the extractant and surfactant concentrations, the mixing speed, the $\mathrm{pH}$ of external or feed phase solution, the concentration of stripping solution, the phase ratio,

\footnotetext{
*Corresponding author: Email: hachemaoui.aziza@yahoo.com
} 
and the treatment ratio, etc, the development of mathematical models describing the process has proven to be difficult. One of the best strategies is to design an experiment. ${ }^{18,19}$ The design of experiments methodology allows, from a fewer number of runs, to extract meaningful information on the studied process.

In the present study, extraction of cerium (III) by emulsion liquid membrane was investigated using bis-(2-ethylhexyl) phosphoric acid (D2EHPA) as extractant, Span 80 as surfactant and $\mathrm{HCl}$ as stripping reagent. Various parameters such as stirring speed, feed solution $\mathrm{pH}$, surfactant concentration, extractant concentration, strip phase concentration, treatment ratio and phase ratio were experimentally studied and the optimum conditions were determined. Then, three operating factors, namely, surfactant concentration, the ratio of stripping to membrane phase (phase ratio: $\mathrm{V}_{\mathrm{s}} / \mathrm{V}_{\mathrm{m}}$ ), and the ratio of emulsion to feed phase (treatment ratio: $\mathrm{V}_{\mathrm{e}} / \mathrm{V}_{\mathrm{f}}$ ), were chosen as independent variables to model the extraction of $\mathrm{Ce}(\mathrm{III})$ from aqueous solution by emulsion liquid membrane with a $2^{3}$ full factorial design.

\section{EXPERIMENTAL}

\section{Reagents}

(D2EHPA) and Sorbitane monooleate (Span 80) were supplied by Cytec Inc and sigma-Aldrich respectively. n-heptane and hydrochloric acid were obtained from Fluka. Cerium stock solutions were prepared by dissolving $\mathrm{CeCl}_{3} .6$ $\mathrm{H}_{2} \mathrm{O}$ in distilled water. All this reagents were used as received.

\section{Emulsion liquid membrane (ELM) procedure}

In the first step, in $100 \mathrm{~mL}$ beaker, the primary emulsion of type water in oil $(\mathrm{W} / \mathrm{O})$ was prepared by emulsification of desired amounts of n-heptane as organic phase, span 80 as surfactant, hydrochloric acid aqueous solution as internal (stripping) phase using a motor driven model RE-166(IKAWerk, Germany) at mixing speed of $2000 \mathrm{rpm}$. The solution was stirred continuously for 20 minutes, so that the mixture of the membrane and the stripping solutions were emulsified. In the second step, in the $250 \mathrm{~mL}$ beaker, the primary emulsion was dispersed into the external phase containing cerium under agitation. The external phase was separated from the emulsion phase by decantation. The uptake of the Ce (III) ions was monitored by removing samples of the feed phase periodically for analysis by Arsenazo-III visible spectrophotometric method.

\section{Experimental design Methodology}

For the elimination process of Ce (III) by emulsion liquid membrane, three important operating parameters such as surfactant concentration ([span 80]), treatment ratio $\left(\mathrm{V}_{\mathrm{m}} / \mathrm{V}_{\mathrm{e}}\right)$, and phase ratio $\left(\mathrm{V}_{\mathrm{s}} / \mathrm{V}_{\mathrm{m}}\right)$ were chosen as the independent variables and designated as $\mathrm{X}_{1}, \mathrm{X}_{2}$, and $\mathrm{X}_{3}$, respectively. To evaluate the influence and interactions of these parameters on the extraction percent of cerium (III), a $2^{3}$ factorial design was used.
The correlation of independent variables and the response were estimated by a first-order polynomial eq. 1 as shown below: ${ }^{20}$

$y=b_{0}+b_{1} x_{1}+b_{2} x_{2}+b_{3} x_{3}+b_{12} x_{1} x_{2}+b_{13} x_{1} x_{3}+b_{23} x_{2} x_{3}+b_{123} x_{1} x_{2} x_{3}+\varepsilon(1)$

The response of the experiments y was measured in term of extraction percent of cerium defined by Eq. (2):

$$
\% y=\left[\frac{\left.C_{0 e x t} \times V_{0 e x t}-C_{\text {fext }} \times V_{\text {fext }}\right)}{C_{0 e x t} \times V_{0 e x t}}\right] \times 100
$$

where,

$\mathrm{C}_{\text {0ext }}, \mathrm{V}_{\text {0ext }}$ : initial concentration and volume of external phase $\mathrm{C}_{\text {fext }}, \mathrm{V}_{\text {fext }}$ : final concentration and volume of external phase, respectively

$b_{0}, b_{1}, b_{2}, b_{3}, b_{12}, b_{13}, b_{23}$, and $b_{123}$ : are regression coefficients, called, respectively, constant term $\left(b_{0}\right.$ is the average response in a factorial experiment), linear terms, and linear interaction terms.

In equation $1, X_{j}$ are dimensionless variables that correspond to $Z_{j}$ and are related by the following standardized forms:

$$
\begin{gathered}
x_{j}=\frac{z_{j}+z_{j}^{0}}{\Delta z_{j}} \quad \mathrm{j}=1,2, \ldots . . \mathrm{k} \\
z_{j}^{0}=\frac{z_{j \max }+z_{j \min }}{2} \\
\Delta z_{j}=\frac{z_{j \max }-z_{j \min }}{2}
\end{gathered}
$$

here, $Z_{j \max }$ and $Z_{j \min }$ represent the maximum and the minimum level of factor $j$ in the natural unit, respectively.

The coefficients of the fitted equation can be obtained from eq. 1 as follows: $:^{20}$

$$
\begin{gathered}
b_{0}=\frac{1}{N} \sum_{i=1}^{N} y_{i} \\
b_{j}=\frac{1}{N} \sum_{i=1}^{N} x_{j i} y_{i} \quad \mathrm{j}=1, \ldots .3 \\
b_{j k}=\frac{1}{N} \sum_{i=1}^{N} x_{j i} x_{k i} y_{i} \quad \text { for } \mathrm{k}=1,2,3 ; \mathrm{j}=1,2,3 ; \text { and } \mathrm{j} \neq \mathrm{k} . \\
b_{123}=\frac{1}{N} \sum_{i=1}^{N} x_{1 i} x_{2 i} x_{3 i} y_{i}
\end{gathered}
$$

Three tests are required to evaluate the adequacy of the model, which are: Cochran test (to verify the homogeneity of variances), Student test " $t$ " (to determine the significance of coefficients of the regression) and the Fisher test for reliability of predicting the regression equation.

\section{RESULTS AND DISCUSSION}

\section{Emulsion liquid membrane (ELM)}

\section{Effect of the equilibrium $\mathrm{pH}$}

The $\mathrm{pH}$ of the feed solution has a profound influence on the extraction behaviour. The effect of $\mathrm{pH}$ in the feed solution on the extraction efficiency 
of cerium was investigated in the range 2.98-5.68. The results, presented in Fig.1, show that by increasing $\mathrm{pH}$ of the feed solution the percentage extraction of cerium increased. Because generally the extraction of lanthanides by an ion exchange mechanism is heavily dependent upon the equilibrium $\mathrm{pH}$ of the aqueous phase according to the following reaction: ${ }^{12}$

$$
L n^{+3}+3 H R \Leftrightarrow \overline{\operatorname{LnR}}+3 H^{+3}
$$

where $\mathrm{Ln}^{+3}$ are trivalent lanthanides, HR is the extractant in free form and the bar refers to the organic phase.

Thus, as $\mathrm{pH}$ increases the $\mathrm{H}^{+}$concentration diminishes and the equilibrium will be shifted towards the right. However, a limit is imposed by the hydrolysis of cerium (hydroxide precipitation) at higher $\mathrm{pH}$ values.

\section{Effect of stripping phase concentration}

The capacity of the emulsion to extract solute is limited by the stripping capacity of the internal solution. ${ }^{21}$ In the present work, the effects of three concentrations of $\mathrm{HCl}$ stripping solutions $(0.5 \mathrm{M}$, $1 \mathrm{M}$, and $2 \mathrm{M}$ ) on the extraction rate of cerium were investigated and the results obtained were shown in Fig. 2. As seen from Fig. 2, the stripping efficiency decrease with an increase in $\mathrm{HCl}$ concentration of the stripping solution from $0.5 \mathrm{M}$ to $2 \mathrm{M}$. This was a result of the increases in the ionic strength difference between internal and external phases that resulted in an increase in swelling, which resulted in greater amounts of water to permeate through the membrane causing the internal droplets to swell and coalesce. ${ }^{13}$ Therefore, $\mathrm{HCl}$ concentration of $0.5 \mathrm{M}$ is chosen as the best stripping solution concentration.

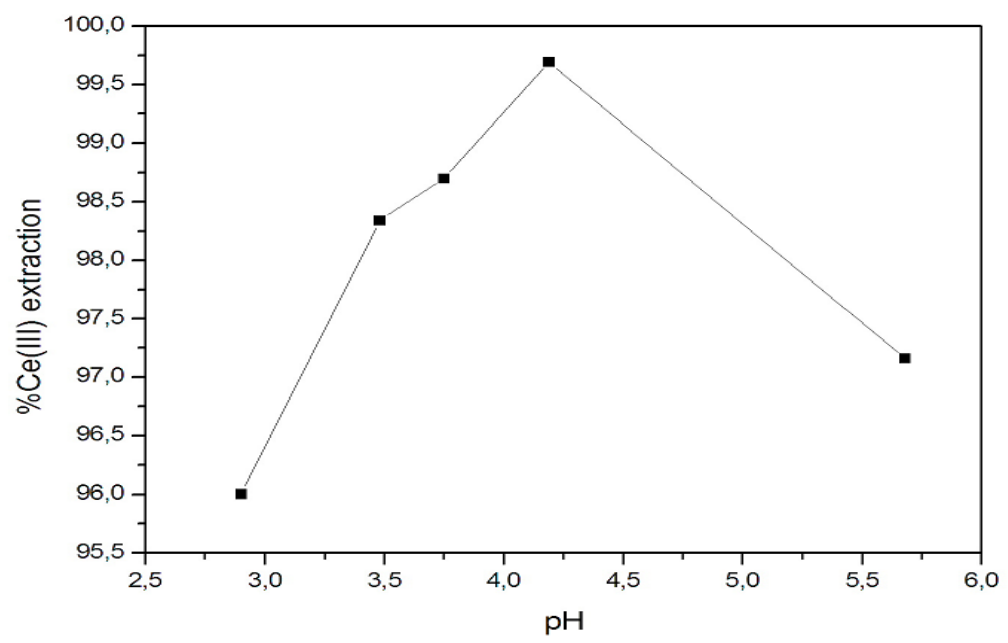

Fig. 1 - Effect of equilibrium $\mathrm{pH}$ on the extraction efficiency of Ce (III):[SPAN 80]: 3.0\%, [HCl]: 0.5M, stirring speed: 700rpm, treatment ratio: 1:5, phase ratio: 1 , [D2EHPA]: $4 \%$, initial Ce (III) concentration in the feed solution $\mathrm{C}_{0}: 250 \mathrm{ppm}$.

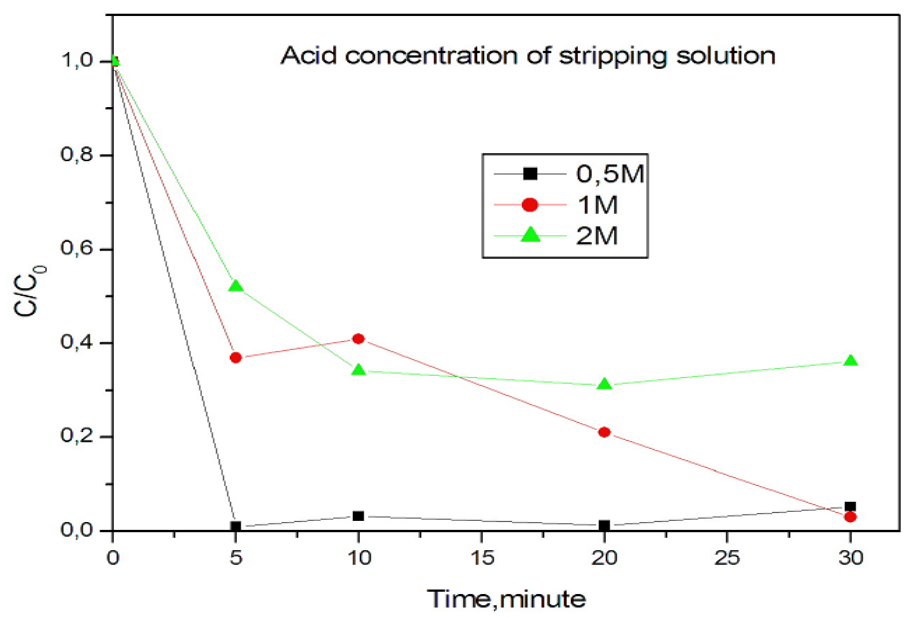

Fig. 2 - Effect of extractant concentration on the extraction rate of Ce (III): [SPAN 80]: 3.0\%, [D2EHPA]: 4\%, stirring speed: 700rpm, treatment ratio: 1:5, phase ratio: $1, \mathrm{pH}$ feed solution: 4.25, initial Ce (III) concentration in the feed solution $\mathrm{C}_{0}: 250 \mathrm{ppm}$. 


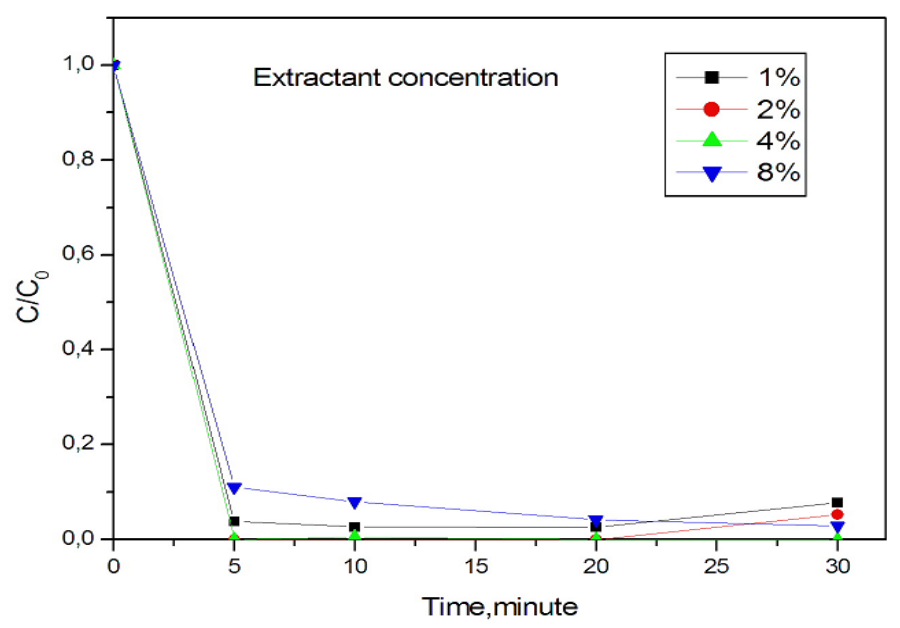

Fig. 3 - Effect of extractant concentration on the extraction rate of Ce (III): [SPAN 80]: 3.0\%, [HCl]: 0.5M, stirring speed: 700rpm, treatment ratio: $1: 5$, phase ratio: $1, \mathrm{pH}$ feed solution: 4.25 , initial Ce (III) concentration in the feed solution $\mathrm{C}_{0}: 250 \mathrm{ppm}$.

\section{Effect of extractant concentration}

The effect of carrier concentration on the extraction rate of cerium is displayed in Fig.3. The result revealed that increasing the extractant concentration in the membrane of the emulsion from $1 \%$ to $2 \%(\mathrm{v} / \mathrm{v})$ leads to an increase in extraction of cerium from aqueous chloride solution, but a further increase in extractant concentration to $8 \%$ results in a very light decrease in the extent of extraction. It is well known that the rate of facilitated transport of the solute is directly affected by the amount of extractant that is present in the emulsion liquid membrane. A very high content of extractant in the membrane does not result in a benefit due to the respective increase in viscosity, which leads to larger globules. ${ }^{22}$ Fig.3 revealed also no significant change in the rate of extraction for D2EHPA concentration of between 2\% to $4 \%$. Therefore, D2EHPA of $2 \%$ is chosen as the best carrier concentration.

\section{Effect of surfactant concentration}

Surfactant concentration is an important factor as it directly affects the stability of ELM [23]. Fig. 4 represents the variation of extraction rate of cerium for various Span 80 concentrations. It was observed from Fig. 4 that at lowest surfactant concentration $(1 \%(\mathrm{~m} / \mathrm{v}))$, emulsions break easily leading to poor extraction efficiency. However, at higher surfactant concentration $(6 \% \quad(\mathrm{~m} / \mathrm{v}))$, although the membrane stability increases, mass transfer resistance also increases due to a higher viscosity of the $\mathrm{W} / \mathrm{O}$ emulsion, resulting in less extraction of cerium ions to stripping solution [24]. Also, it is observed from Fig.4 that for surfactant concentration of $2 \%$ and $3 \%$ the two curves converge. Hence, surfactant concentration of $2 \%$ $(\mathrm{m} / \mathrm{v})$ was chosen as optimum concentration.

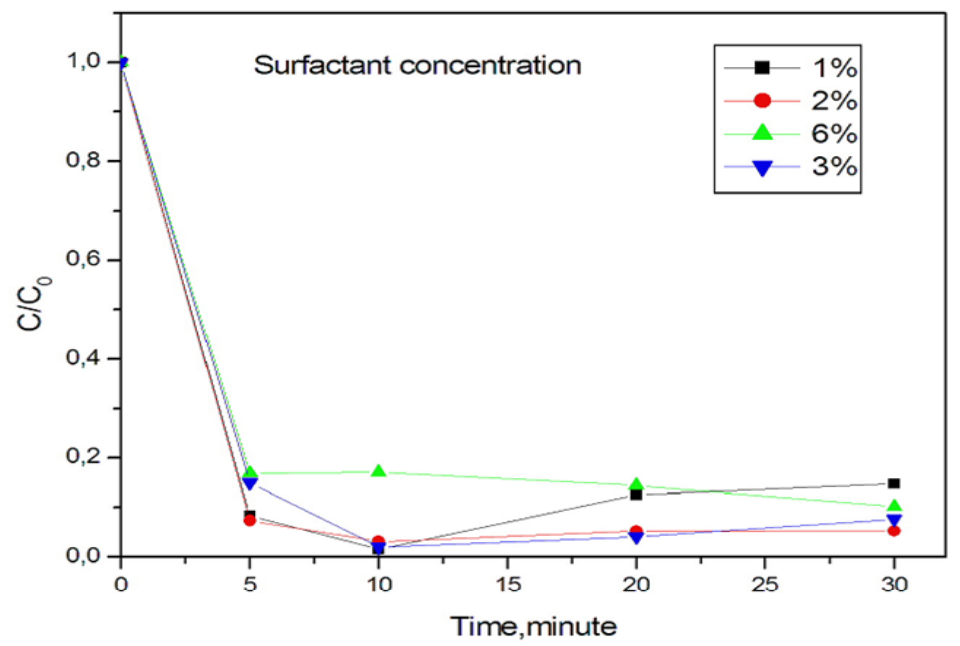

Fig. 4 - Effect of surfactant concentration on the extraction rate of Ce (III): [D2EHPA]: 2\%, [HCl]: 0.5M, stirring speed: 700rpm, treatment ratio: 1:5, phase ratio: $1, \mathrm{pH}$ feed solution: 4.25 , initial Ce (III) concentration in the feed solution $\mathrm{C}_{0}: 250 \mathrm{ppm}$. 


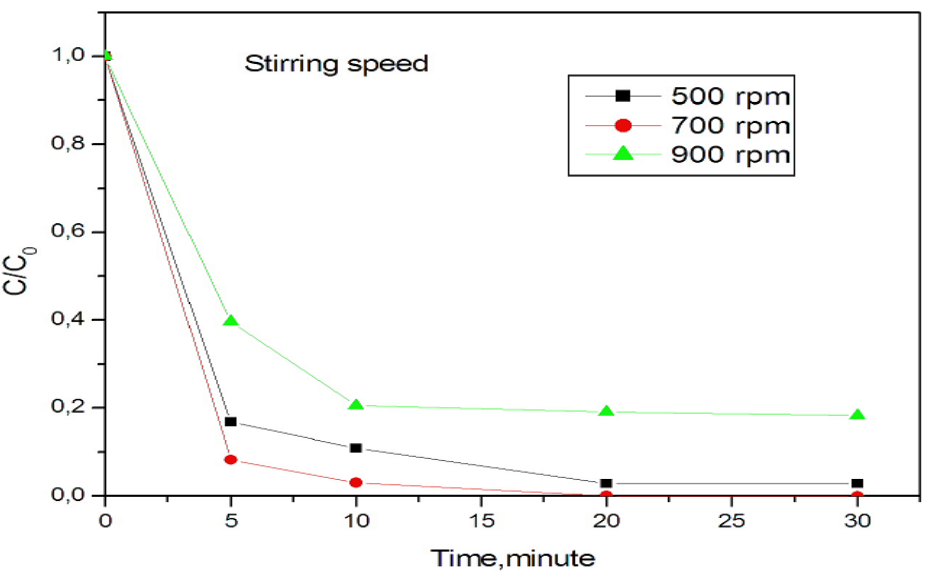

Fig. 5 - Effect of stirring speed on the extraction rate of c Ce (III): [SPAN 80]: 2.0\%, [D2EHPA]:2\%, [HCl]:0.5M, treatment ratio: 1:5, phase ratio: $1, \mathrm{pH}$ feed solution: 4.25 , initial Ce (III) concentration in the feed solution $\mathrm{C}_{0}: 250 \mathrm{ppm}$.

\section{Effect of stirring speed}

Stirring speed during extraction with ELM is an important factor. Effects of stirring speed on the extraction rate of cerium are studies in the range of 500 through $900 \mathrm{rpm}$ and shown in Fig.5. It was observed that when stirring speed increased from $500 \mathrm{rpm}$ to $700 \mathrm{rpm}$, the rate of extraction increased. Because as the stirring speed increases, smaller sized emulsion droplets were formed leading to more surface area for mass transfer. This increased transfer area allows the extraction to occur at a higher rate. However, it is not possible to increase the rotating speed over $700 \mathrm{rpm}$ without having breaking of emulsion and leakage of the solute into the feed phase from the stripping phase (emulsion formed at $900 \mathrm{rpm}) .{ }^{21}$ Hence, the stirring speed was taken as $700 \mathrm{rpm}$ to ensure a good stability of the $\mathrm{W} / \mathrm{O}$ emulsions and to enhance the interfacial area available for mass transfer.

\section{Effect of phase ratio}

The phase ratio, defined as the ratio of strip phase volume $\left(\mathrm{V}_{\mathrm{s}}\right)$ to the membrane phase volume $\left(\mathrm{V}_{\mathrm{m}}\right)$ plays an important role in determining the effectiveness of ELMs. ${ }^{23}$ The effect of phase ratio $\left(\mathrm{V}_{\mathrm{s}} / \mathrm{V}_{\mathrm{m}}\right)$ is illustrated in Fig. 6. The result showed that as phase ratio increased from 0.25 to 1.0, extraction efficiency of cerium increased. Because when phase ratio is large, the emulsion globules are more densely packed with internal stripping phase droplets resulting in a decrease of the diffusion path length for $\mathrm{Ce}$ (III)-extractant complex within the emulsion globule prior to getting stripped. ${ }^{21}$ But, further increase in the phase ratio to 1.5 decreases extraction efficiency of $\mathrm{Ce}$ (III) as the stability of emulsion and membrane thickness decreases. From these results, phase ratio of 1 was accepted as the best ratio.

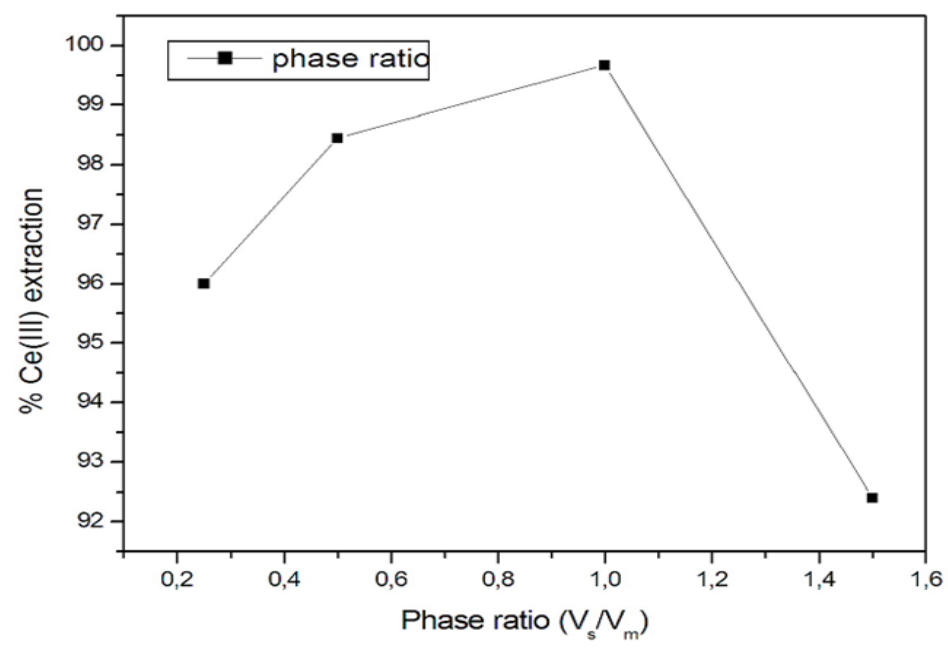

Fig. 6 - Effect of phase ratio on the extraction efficiency of Ce (III): [SPAN 80]: 2.0\%, [D2EHPA]:2\%,

$[\mathrm{HCl}]: 0.5 \mathrm{M}$, treatment ratio: $1: 5, \mathrm{pH}$ feed solution: 4.25 , initial Ce (III) concentration in the feed solution $\mathrm{C}_{0}: 250 \mathrm{ppm}$. 


\section{Effect of treatment ratio}

Treatment ratio defined as the ratio of emulsion phase volume $(\mathrm{Ve})$ to the feed phase $\left(\mathrm{V}_{\mathrm{f}}\right)$, controls interfacial mass transfer across ELMs. ${ }^{23}$ The effect of treatment ratio on the extraction efficiency of cerium is illustrated in Fig. 7. The result showed that an increase in treatment ratio, leads to an increase in the extraction efficiency, because the volume of both the carrier and stripping reagent, i.e. the volume of emulsion as whole increased. Therefore, the surface area for mass transfer owing to the formation of a large number of emulsion globules increased. Hence, treatment ratio of 0.2 was accepted as the best ratio.

\section{Design experiment}

For the elimination process of Ce (III) by emulsion liquid membrane, three important operating parameters such as surfactant concentration ([span 80]), treatment ratio $\left(\mathrm{V}_{\mathrm{m}} / \mathrm{V}_{\mathrm{e}}\right)$, and phase ratio $\left(\mathrm{V}_{\mathrm{s}} / \mathrm{V}_{\mathrm{m}}\right)$ were chosen as the independent variables and designated as $\mathrm{X}_{1}, \mathrm{X}_{2}$, and $\mathrm{X}_{3}$, respectively. To evaluate the influence and interactions of these parameters on the extraction percent of cerium (III), a $2^{3}$ factorial design was used. The original values of each factor and their corresponding levels are presented in Table 1.

Table 2 regroups the results for the design matrix for $\mathrm{k}=3, \mathrm{~N}=8$, and $\mathrm{m}=5$.

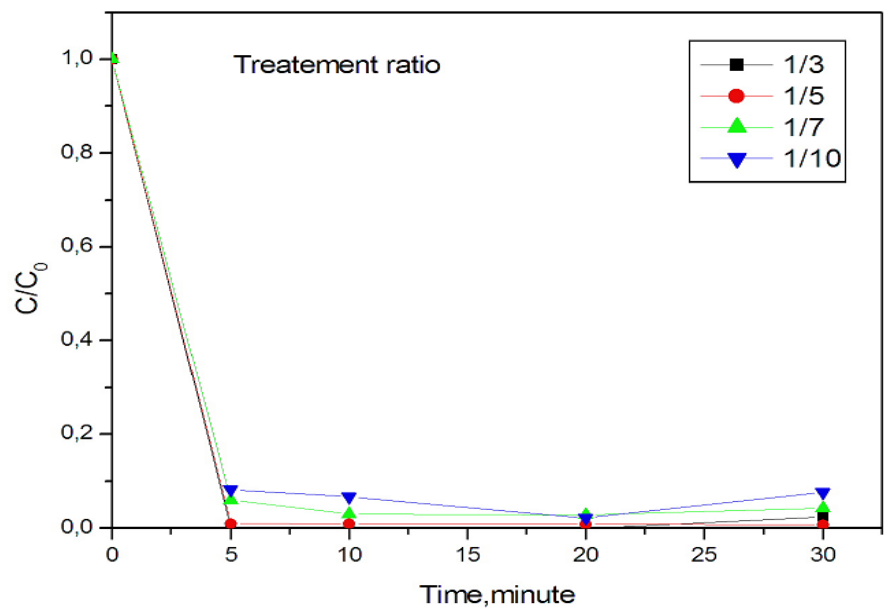

Fig. 7 - Effect of treatment ratio on the extraction rate of Ce (III): [SPAN 80]: 2.0\%,

[D2EHPA]:2\%, [HCl]:0.5M, phase ratio: $1, \mathrm{pH}$ feed solution: 4.25 , initial Ce (III) concentration in the feed solution $\mathrm{C}_{0}: 250 \mathrm{ppm}$.

Table 1

Values of operating factors at Two Levels

\begin{tabular}{llc}
\hline Operating factors & \multicolumn{1}{c}{ levels } \\
\hline & -1 & +1 \\
\hline $\mathrm{Z}_{1}:$ surfactant concentration:[span80] $(\mathrm{m} / \mathrm{v})$ & 2 & 6 \\
$\mathrm{Z}_{2}:$ phase ratio: $\mathrm{V}_{\mathrm{s}} / \mathrm{V}_{\mathrm{m}}$ & 0.5 & 1 \\
$\mathrm{Z}_{3}:$ traitement ratio $: \mathrm{Ve} / \mathrm{V}_{\mathrm{f}}$ & 0.1 & 0.4 \\
\hline
\end{tabular}

Table 2

Design matrix for $\mathrm{k}=3, \mathrm{~N}=8$, and $\mathrm{m}=5$

\begin{tabular}{l|l|l|l|l|l|l|l|l}
\hline run N & $\mathbf{1}$ & $\mathbf{2}$ & $\mathbf{3}$ & $\mathbf{4}$ & $\mathbf{5}$ & $\mathbf{6}$ & $\mathbf{7}$ & $\mathbf{8}$ \\
\hline [span80] & 2 & 6 & 2 & 6 & 2 & 6 & 2 & 6 \\
$\mathrm{~V}_{\mathrm{s}} / \mathrm{V}_{\mathrm{m}}$ & 0.5 & 1 & 0.5 & 1 & 0.5 & 1 & 0.5 & 1 \\
$\mathrm{~V}_{\mathrm{e}} / \mathrm{V}_{\mathrm{f}}$ & 0.1 & 0.4 & 0.1 & 0.4 & 0.1 & 0.4 & 0.1 & 0.4 \\
$\mathrm{X}_{1}$ & -1 & 1 & -1 & 1 & -1 & 1 & -1 & 1 \\
$\mathrm{X}_{2}$ & -1 & -1 & 1 & 1 & -1 & -1 & 1 & 1 \\
$\mathrm{X}_{3}$ & -1 & -1 & -1 & -1 & 1 & 1 & 1 & 1 \\
$\mathrm{Y}_{1}, \%$ & 88.56 & 97.53 & 97.01 & 91.31 & 100.00 & 97.83 & 99 & 96.66 \\
$\mathrm{Y}_{2}, \%$ & 89.26 & 97.66 & 97.15 & 91.4 & 100.00 & 97.91 & 99.08 & 97.33 \\
$\mathrm{Y}_{3}, \%$ & 89.29 & 97.71 & 97.16 & 91.07 & 100.00 & 97.91 & 99.09 & 97.15 \\
$\mathrm{Y}_{4}, \%$ & 89.29 & 97.62 & 97.16 & 90.94 & 100.00 & 97.76 & 98.83 & 97.12 \\
$\mathrm{Y}_{5}, \%$ & 89.26 & 96.46 & 97.10 & 91.01 & 100.00 & 97.87 & 99.11 & 97.35 \\
$\bar{Y}, \%$ & 89.13 & 97.40 & 97.12 & 91.15 & 100.00 & 97.86 & 99.02 & 97.12 \\
\hline
\end{tabular}




\section{Statistical analysis}

\section{Cochran Test}

Cochran's test is relatively simple, and its arithmetic is brought down to calculating:

$$
c=\frac{s_{\max }^{2}}{\sum_{i=1}^{N} s_{i}^{2}},
$$

where $s_{\max }^{2}$ the largest variance in a sequence of is tested variances and $\sum_{i=1}^{N} s_{i}^{2}$ is the sum of all variances in the experiment.

For each experiment, the variance is estimated by

$$
s_{i}^{2}=\frac{\sum_{u=1}^{m}\left(y_{i u}-\bar{y}_{i}^{2}\right)}{m-1},
$$

where the average response is

$$
\overline{y_{i}}=\frac{\sum_{u=1}^{m} y_{u i}}{m}
$$

$\sum_{u=1}^{m} y_{u i}$ is the sum of all experimental values for the $\mathrm{i}^{\text {th }}$ observation.

From the literature table of Cochran, we can find $\mathrm{C}_{\alpha}(\mathrm{N}, \mathrm{m}-1)=\mathrm{C}_{0.05}(8,4)=0.5441$, and if $\mathrm{C}=$ $0.5360<\mathrm{C}_{0.05}$ (8. 4), then the variances are homogeneous.

Student Test. The Student's test is given for each effect as follows:

$$
t_{j}=\frac{\left|b_{j}\right|}{s_{b}},
$$

where

$$
\begin{aligned}
S_{b}= & \sqrt{\frac{s_{r e p}^{2}}{m N}} \quad \text { (14) } \quad \text { follows } \\
& \hat{y}=96.0987-0.155 x_{1}+2.4012 x_{3}-1.7487 x_{1} x_{2}+0.7922 x_{1} x_{3} \\
& -0.4307 x_{2} x_{3}+1.8097 x_{1} x_{2} x_{3}
\end{aligned}
$$

$$
s_{\text {rep }}^{2}=\frac{\sum_{i=1}^{N} s_{i}^{2}}{N}
$$

$s_{r e p}^{2}$ is the reproduction variance, and $\mathrm{S}_{\mathrm{b}}$ is the rootmean-square deviation.

The tabulated $\langle\langle\mathrm{t}\rangle\rangle$ value, $\mathrm{t}_{\alpha}(\mathrm{N}(\mathrm{m}-1))=$ $=\mathrm{t}_{0.05}(32)$, is found to be between 1.684 and 1.697, seeing that only $t_{2}$ is less than the tabulated value, then the corresponding coefficient $b_{2}$ is not significant; therefore, it is excluded from the regression equation.

Fisher Test. The F-test is given by:

$$
F=\frac{s_{r e s}^{2}}{s_{r e p}^{2}},
$$

where $S_{r e s}^{2}$ is the residual variance.

$$
s_{r e s}^{2}=\frac{m \sum_{i=1}^{N}\left(\bar{y}-\hat{y}_{i}\right)^{2}}{N-l}
$$

$\hat{y}_{i}$ is the calculated value of the response for the $i$ th observation.

1 is the number of significant coefficient in the regression equation (here it is equal to 7).

Table 3 gives the values of $s_{r e p}^{2}, s_{\text {res }}^{2}$, and $\mathrm{F}$ estimated for the regression equation. The lower degree of freedom $\left(f_{1}=\mathrm{N}-1\right)$ and the upper degree of freedom $\left(\mathrm{f}_{2}=\mathrm{N}(\mathrm{m}-1)\right)$ are 1 and 32 , respectively. The tabulated $\mathrm{F}$ value for a $5 \%$ level of significance is between 4.08 and 4.17.

Just as $\mathrm{F}<\mathrm{FTAB}$, it was concluded that the response variation can be explained by the regression.

The coefficient of determination $\mathrm{R}^{2}$ was found to be 0.9981 .

Finally, the model equation for cerium extraction by emulsion liquid membrane is as

Table 3

Fisher Test for the Adequacy of the Regression Equation

\begin{tabular}{l|l|l}
\hline Residual variance $\left(\boldsymbol{s}_{\text {res }}^{2}\right)$ & Reproduction variance $\left(\boldsymbol{s}_{\text {rep }}^{2}\right)$ & Estimed F value \\
\hline 0.1505 & 0.06486 & 2.3204 \\
\hline
\end{tabular}


Table 4

Values of Relatives Errors

\begin{tabular}{l|r|r|r|l|l|l}
\hline $\begin{array}{l}\text { Number of } \\
\text { test }\end{array}$ & $\boldsymbol{x}_{\boldsymbol{1}}$ & $\boldsymbol{x}_{\mathbf{2}}$ & $\boldsymbol{x}_{\mathbf{3}}$ & \multicolumn{1}{|c}{$\overline{\boldsymbol{y}} \boldsymbol{\%}$} & $\hat{\boldsymbol{y}}, \boldsymbol{\%}$ & Relative error,\% \\
\hline 1 & -1 & -1 & -1 & 89.13 & 89.07 & 0.0673 \\
2 & 1 & -1 & -1 & 97.40 & 97.46 & 0.0616 \\
3 & -1 & 1 & -1 & 97.12 & 97.05 & 0.0721 \\
4 & 1 & 1 & -1 & 91.15 & 91.21 & 0.0658 \\
5 & -1 & -1 & 1 & 100.00 & 99.94 & 0.0600 \\
6 & 1 & -1 & 1 & 97.86 & 97.92 & 0.0613 \\
7 & -1 & 1 & 1 & 99.02 & 98.96 & 0.0606 \\
8 & 1 & 1 & 1 & 97.12 & 97.18 & 0.0617 \\
\hline
\end{tabular}

The analysis of the regression equation shows that the principal effect $X_{2}$ (phase ratio) has no influence on the cerium extraction yield in this interval [0.5-1]. The treatment ratio $\left(\mathrm{X}_{3}\right)$ has the strongest effect on the response, the corresponding coefficient $\left(\mathrm{B}_{3}:\right.$ 2.4012) is larger than the coefficients of the other investigated factors.

\section{Comparison with experiments}

Table 4 gives the results of the comparison between average responses given by the experiments and those calculated by the model equation given above, and it shows that the maximum margin between those values for every test is less than $1 \%$. The results showed that the experimental and predicted values were in good agreement.

\section{CONCLUSION}

An emulsion liquid membrane process using D2EHPA as extractant has been successfully applied to extract cerium from chloride solution. In order to achieve the objective optimum conditions have been determined experimentally as stated above. Through this study, we conclude also that cerium (III) extraction with emulsion liquid membrane process can be modelled with a mathematical model of first order with interaction. Statistical analyses showed a high $\mathrm{R}^{2}$ value of regressions model equation $\left(\mathrm{R}^{2}=0.9981\right)$ which ensures a sufficient adjustment of the model with the experimental data. The design of experiments for cerium extraction yield also exhibits the existence of interactions between the various factors studies. This result shows the weakness of conventional methods which do not take into account these effects.

\section{REFERENCES}

1. T. Miaomiao, J. Qiong and L. Wuping, J. rare earths, 2013, 31, 604.

2. D. Renata, Abreu and A. Carlos Morais, Miner. Engi., 2014, 61, 82-87.

3. M. Eskandari Nasab, A. Sam and S. A. Milani, Hydrometallurgy, 2011, 106, 141-147.

4. F. Xie, T. A. Zhang, D. Dreisinger and F. Doyle, Miner. Engi., 2014, 56, 10-28.

5. S. Kumar Sahu and S. Mishra, J. Chem. Techno. Metall., 2015, 50, 255-261.

6. T. Sato, J. Alloys Compd., 1993, 192, 135-137.

7. Y. Cui, J. Yang, G. Yang, G. Xia, Y. Nie and G. Sun, Hydrometallurgy, 2012, 121, 16-21.

8. J. Tang, K. H. Johannesson, Geochim. Cosmochim. Acta, 2010, 74, 6690-6705.

9. X. Suna, H. Luob and S. Dai, Talanta, 2012, 90, $132-137$.

10. D. Abreu and C. A. Morais, Minerals Eng., 2014, 61, 82-87.

11. C. Abbruzzese, P. Fornari, R. Massidda and T. S. Urbanski, Hydrometallurgy, 1992, 28, 179-190.

12. T. S. Urbanski, P. Fornari, and C. Abbruzzese, Hydrometahurgy, 1996, 40, 169-179.

13. A. L. Ahmada, A. Kusumastutia, C. J. C. Dereka and B. S. Ooia, Chem. Eng. J., 2011, 171, 870-882.

14. X. Ll and X. Zhang, J. Membr. Sci., 1997, 128, 223-229.

15. T. Kakoi, T. Nishiyori, T. Oshima, F. Kubota, M. Gotoa, S. Shinkai and F. Nakashio, J. Membr. Sci., 1997, 136, 261-271.

16. T. Kakoia, T. Oshimaa, T. Nishiyoria, F. Kubotaa, M. Gotoa, S. Shinkaia and F. Nakashio, J. Membr. Sci., 1998, 143, 125-135.

17. A. L. Ahmad, A. Kusumastuti, C. J. C. Derek and B. S. Ooi, Desalination, 2012, 287, 30-34

18. F. Valenzuela, C. Fonseca, C. Basualto, O. Correa, C. Tapia and J. Sapag, Miner. Engi., 2005, 18, 33-40.

19. S. Nosrati, N. S. Jayakuma and M. A. Hashim, Desalination, 2011, 266, 286-290

20. V. Kafarov, " Methodes cybernétique et technologie chimique", Edition Mir Moscou, 1974.

21. R. A. Kumbasar, J. Membr. Sci., 2009, 333, 118-124.

22. R. A. Kumbasar, J. Membr. Sci., 2008, 325, 712-718

23. R. A. Kumbasar, Sep. Purif. Techno., 2009, 64, 273-279

24. A. Hachemaoui and K. Belhamel, Int. J. Miner. Process., 2017, 161, 7-12. 